\title{
METOdOLOGIA PARA CÁLCULO DE EFICIÊNCIA DE TÉCNICAS COMPENSATÓRIAS EM LOTE URBANO
}

\section{METHOD FOR PERFORMANCE CALCULATION TECHNIQUES IN URBAN LOT COUNTERVAILING}

\author{
Alfredo Akira Ohnuma Jr \\ Departamento de Engenharia Sanitário e Meio Ambiente/UERJ \\ Eduardo Mario Mendiondo \\ Universidade de São Paulo/USP
}

\begin{abstract}
RESUMO
Loteamentos residenciais ocupados de forma tradicional resultam elevadas cargas nos sistemas de drenagem pluvial. Este artigo propõe analisar a redução da parcela de escoamento superficial na retenção das águas pluviais com técnicas compensatórias incorporadas em lote urbano. O indicativo utilizado para estimar a eficiência teve como referência dados do coeficiente de escoamento em eventos de precipitação não induzidos para cenários com e sem o dispositivo alternativo de retenção. As técnicas monitoradas são consideradas não-convencionais, sendo: trincheira de infiltração e telhado verde. Tratam-se de estruturas de armazenamento que tendem a favorecer a detenção das águas pluviais no lote, contribuindo também no aumento de volumes infiltrados. Durante cerca de 5 meses, o estudo consiste da análise de mais de 120 eventos sub-diários, não induzidos, com monitoramento de níveis que resultaram no cálculo da eficiência da retenção das águas pluviais de cada dispositivo. Os resultados obtidos pelo monitoramento indicaram que a adoção de tais práticas permite uma eficiência na retenção do escoamento de até $80 \%$ quando comparado com uma residência sem uso das técnicas compensatórias. Portanto, o efeito combinado de diferentes medidas potencializa a retenção do escoamento e otimiza a capacidade de reservação da água em escalas de microdrenagem, sobretudo em áreas urbanizadas. Espera-se de futuras pesquisas desenvolver um mecanismo para o sistema de gestão integrada e descentralizada de águas urbanas, com enfoque em drenagem seletiva a partir do aproveitamento de águas pluviais.
\end{abstract}

Palavras-chave: drenagem urbana, técnicas compensatórias, eficiência na retenção, águas pluviais.

\begin{abstract}
Residential lots occupied traditionally result in high loads of stormwater in drainage systems. This article aims to analyze the reduction of runoff in storm water retention with compensatory techniques incorporated into urban lot. The index used to estimate the efficiency was as reference data the flow coefficient precipitation events uninduced for scenarios with and without the alternative retaining means. Technical monitored are considered unconventional, as follows: infiltration trench and green roof. These are storage structures that tend to favor the arrest of rainwater on the lot, also contributing to the increase of infiltrated volumes. For about 5 months, the study analysed of more than 120 sub-daily events, not-induced with monitoring levels which resulted in the calculation of efficiency of retention of stormwater each techniques. The results of the monitoring indicated that the adoption of such practices allows efficient retention of the flow of up to $80 \%$ when compared to a residence without use of compensatory techniques.
\end{abstract}


Therefore, the combined effect of different measures enhances the retention of the reservation flow and optimizes the capacity of the water microdrainage ranges, particularly in urban areas. It is expected that future research to develop a mechanism for the system in an integrated and decentralized urban water management, focusing on selective drainage from the rainwater harvesting.

Keywords: urban drainage, compensatory techniques, efficient retention, rainwater.

\section{INTRODUÇÃO}

Eventos pluviométricos extremos sobrecarregam redes de drenagem, cuja incapacidade para transportar elevados volumes de escoamento superficial provocam o extravazamento de canais e conseqüentemente às inundações urbanas. Nessas condições, em períodos de cheias, ao escoar por determinada superfície de captação, as águas pluviais carregam poluentes capazes de transmitir doenças de veiculação hídrica, como: hepatite $A$, ascaridíase, esquistossomose, gastroenterite, amebíase, cólera e outras. Além disso, o desenvolvimento da urbanização sem o adequado planejamento nas cidades favorece o desencadeamento de uma série de problemas de infraestrutura urbana, principalmente a partir da má distribuição do uso e da ocupação do solo em áreas de risco e próximo das margens dos rios. Diferentes tipos de cobertura do solo desempenham funções variadas na geração do escoamento (WEl et al., 2014). A impermeabilização do solo devido à construção de loteamentos residenciais com áreas de coberturas de edificações, telhados, áreas de estacionamento, ruas pavimentadas e calçamentos, portanto provocam um aumento da parcela de volume de chuva que é convertida em escoamento superficial. Esse processo de ocupação de áreas vegetadas ocorre à medida que cresce a densidade populacional e de edificações. Diferentes cidades do Brasil apresentaram taxas de impermeabilização de até $70 \%$ na correlação da densidade populacional e registros de áreas impermeáveis de 15 domicílios/hectare (PINTO e MARTINS, 2008).

O entendimento dos processos que envolvem sistemas interligados, principalmente em áreas urbanas, exige conhecimento e compreensão detalhados dos fenômenos em escala de disciplinas interligadas. Comparado com as áreas rurais, o uso da terra em áreas urbanas prevê processos mais dinâmicos hidrologicamente. Subseqüentemente, processos relacionados ao balanço hídrico como a evapotranspiração, o fluxo da água subterrânea, o 
movimento da umidade do solo e o transporte de contaminantes menos compreendidos (RAGAB et al., 2003). O uso da terra é fator determinante no teor de umidade de solo, sobretudo quando há variação da profundidade do tipo de cobertura do solo (YANG et al., 2014), o que pode afetar diretamente as condições do escoamento e armazenamento das águas pluviais.

Dados observados em áreas urbanas para o cálculo do balanço hídrico são escassos, além de possuírem incertezas consideráveis em muitos dos seus componentes (OWEN, 1995; VAN DEN VEN, 1990; LERNER, 1997; GRIMMOND AND OKE, 1991; WHITLOW et al., 1992; STEPHENSON, 1994). É necessário realizar coleta de dados reais, sendo úteis, tanto para a gestão das águas como para a calibração de modelos hidrológicos e hidrodinâmicos de projetos sistêmicos e urbanos.

Ao incorporar medidas de controle para verificação de sua eficiência, a coleta de dados é indispensável para uma análise no sistema de reservação da água. Para as diferentes medidas potencialmente utilizáveis para o controle do escoamento, sua classificação deve-se ao componente de atuação na drenagem, com lâminas d'água precipitáveis de controle do volume e análise da qualidade da água. A principal medida com atuação local são aquelas de controle na fonte, sendo primárias de desenvolvimento (TUCCI, 2004).

Segundo MCCUEN \& MOGLEN (1988), a principal intenção das bacias de detenção é diminuir as conseqüências hidrológicas da perda do armazenamento natural devido à urbanização. Os critérios de gerenciamento, durante vários anos, buscavam apenas o controle das vazões de pico, esquecendo-se das interferências relacionadas à erosão das margens e qualidade da água. Assim, tornou-se primariamente fundamental avaliar critérios variados para o dimensionamento e a escolha das melhores alternativas para o controle das vazões de pico.

A utilização de pequenas cisternas em lotes urbanos foi testada por SCHILLING (1982) como medida não-convencional simples e barata visando diminuir os efeitos da urbanização. Os resultados para uma bacia com $29 \%$ de área impermeável e implantação de 140 cisternas de 0,5 $\mathrm{m}^{3}$ indicaram redução das vazões pico de até $20 \%$. No entanto para eventos mais freqüentes com período de retorno menor que 1 ano, as vazões diminuíram em até $80 \%$. Áreas incorporadas por telhados verdes apresentam uma maior eficiência na sua 
capacidade de absorção de água pluvial em relação a um telhado convencional, com uma retenção de aproximadamente $56 \%$ do volume precipitado (OHNUMA JR, ALMEIDA NETO e MENDIONDO, 2014).

Dentre as alternativas consideradas como compensatórias do efeito da urbanização ou de uso e ocupação no solo utilizadas neste estudo são: trincheira de infiltração e telhado verde. Este trabalho tem como objetivo estimar a eficiência na retenção de águas pluviais com aplicação de técnicas compensatórias de controle alternativo e enfoque no coeficiente de escoamento para cenário sem controle e cenário com controle.

\section{MATERIAIS E MÉTODOS}

A área de estudo onde foram testadas as técnicas compensatórias pertence ao Condomínio Residencial Samambaia localizado no extremo norte do município de São Carlos-SP, distante $230 \mathrm{Km}$ do município de São PauloSP. Está inserida na bacia hidrográfica do Córrego do Jararaca, afluente do Rio Mogi Guaçu. A precipitação média anual na região é de $1400 \mathrm{~mm}$, com temperaturas máxima e mínima de $27^{\circ} \mathrm{C}$ e 15 (CEPAGR I, 2015).

O total precipitado de $1083 \mathrm{~mm}$ pela estação pluviométrica localizada na própria área de estudo corresponde ao período de monitoramento observado entre 13/11/2006 e 19/03/2007 (Figura 1). Precipitações observadas por estações vizinhas a área deste estudo foram utilizadas de forma avaliar os resultados de consistência dos dados pluviométricos.

Figura 1. Total pluviométrico diário observado no período de análise $(\mathrm{mm})$ :

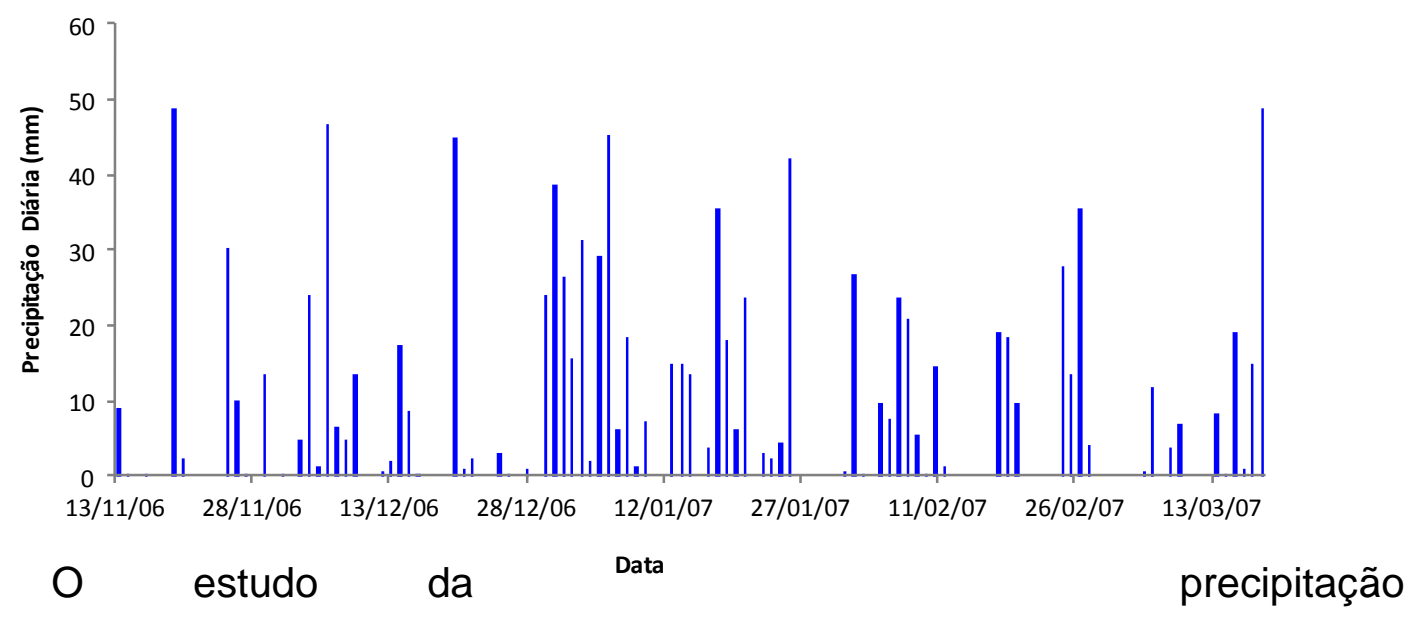

observada pelo monitoramento do lote é obtido por análise de consistência pelo Método da Curva Dupla Massa, utilizado para séries históricas completas e 
mensais. O método consiste da elaboração de um gráfico cartesiano onde se relacionam os totais mensais acumulados do posto observado nas ordenadas e dos postos vizinhos nas abcissas. Considera-se que os valores têm consistência quando há proporcionalidade nos valores do posto em análise aos dados observados pelos postos vizinhos a partir do alinhamento obtido por uma reta, cuja declividade determina o fator de proporcionalidade entre as séries.

Os dados de precipitação de estações vizinhas consistem dos postos pluviométricos do: Centro Integrado de Informações Agrometeorológicas (CIIAGRO, 2014), Departamento de Águas e Energia Elétrica (DAEE, 2014) e Instituto Nacional de Meteorologia (INMET, 2014), todas localizadas no município de São Carlos-SP (Tabela 1).

Tabela 1. Coordenadas geográficas de estações no município de São Carlos-SP e totais pluviométricos mensais $(\mathrm{mm})$ :

\begin{tabular}{ccccc}
\hline Coord/Mês & Lote $^{(1)}$ & Ciiagro $^{(1)}$ & DAEE $^{(2)}$ & INMET $^{(3)}$ \\
\hline Latitude S & $2157^{\prime} 30^{\prime \prime}$ & $2201^{\prime} 00^{\prime \prime}$ & $2153^{\prime} 00^{\prime \prime}$ & $2201^{\prime} 00^{\prime \prime}$ \\
\hline Longitude O & $4753^{\prime} 00^{\prime \prime}$ & $4753^{\prime} 00^{\prime \prime}$ & $4753^{\prime} 00^{\prime \prime}$ & $4754^{\prime} 00^{\prime \prime}$ \\
\hline Distância do Lote $(\mathrm{km})$ & --- & 6,70 & 8,30 & 7,00 \\
\hline Nov & 158,5 & 146,8 & 147,9 & 164,6 \\
Dez & 246,4 & 233,0 & 244,5 & 270,0 \\
Jan & 453,7 & 328,8 & 253,7 & 260,2 \\
Fev & 239,6 & 205,0 & 218,8 & 217,3 \\
Mar & 148,8 & 158,0 & 174,4 & 171,0 \\
\hline Total & 1247,0 & 1071,6 & 1039,3 & 1083,1 \\
\hline
\end{tabular}

NOTA: (") 2006 e 2007; (1) Média mensal entre 1992 e 2014; ${ }^{(2)}$ Média mensal entre 1970 e 1995; ${ }^{(3)}$ Média mensal entre 1962 e 1998.

Após análise da consistência dos dados pluviométricos a partir do Método de Curva de Dupla Massa obteve-se a caracterização do período hidrológico do monitoramento, compreendido entre 13/11/2006 e 19/03/2007. Os dados agrupam-se em mais de 120 eventos sub-diários distribuídos em 84 dias com registros de precipitação, o que resulta quase $70 \%$ do período classificado como úmido ou com algum evento sub-diário registrado. As intensidades pluviométricas calculadas estão entre 2 e $75 \mathrm{~mm} / \mathrm{h}$, com duração máxima de precipitação encontrada de 276 minutos ou 4 horas e 36 minutos.

O condomínio possui área total aproximada de 36 ha, composto por 7,5 hectares de áreas de lazer, 12 hectares de arruamentos do tipo asfáltico e 16,5 hectares ou $46 \%$ do total loteado de lotes para ocupação residencial. Até meados do ano 2014, praticamente todos os lotes estavam ocupados por edificações, com pequena parcela de solo exposto. O lote experimental deste estudo possui área total de $500 \mathrm{~m}^{2}$, com área de contribuição de $160 \mathrm{~m}^{2}$ para a 
trincheira de infiltração, conforme declividade do terreno, correspondente a 120 $\mathrm{m}^{2}$ de grama e $40 \mathrm{~m}^{2}$ de concreto. $O$ telhado verde consiste de área de cobertura de cerca de $10 \mathrm{~m}^{2}$, com diversas espécies de plantio de hortaliças e composto de substrato orgânico. A Figura 1 ilustra a localização do loteamento na Bacia do Córrego do Jararaca e áreas do lote com respectivas técnicas compensatórias (Ohnuma Jr, 2008).
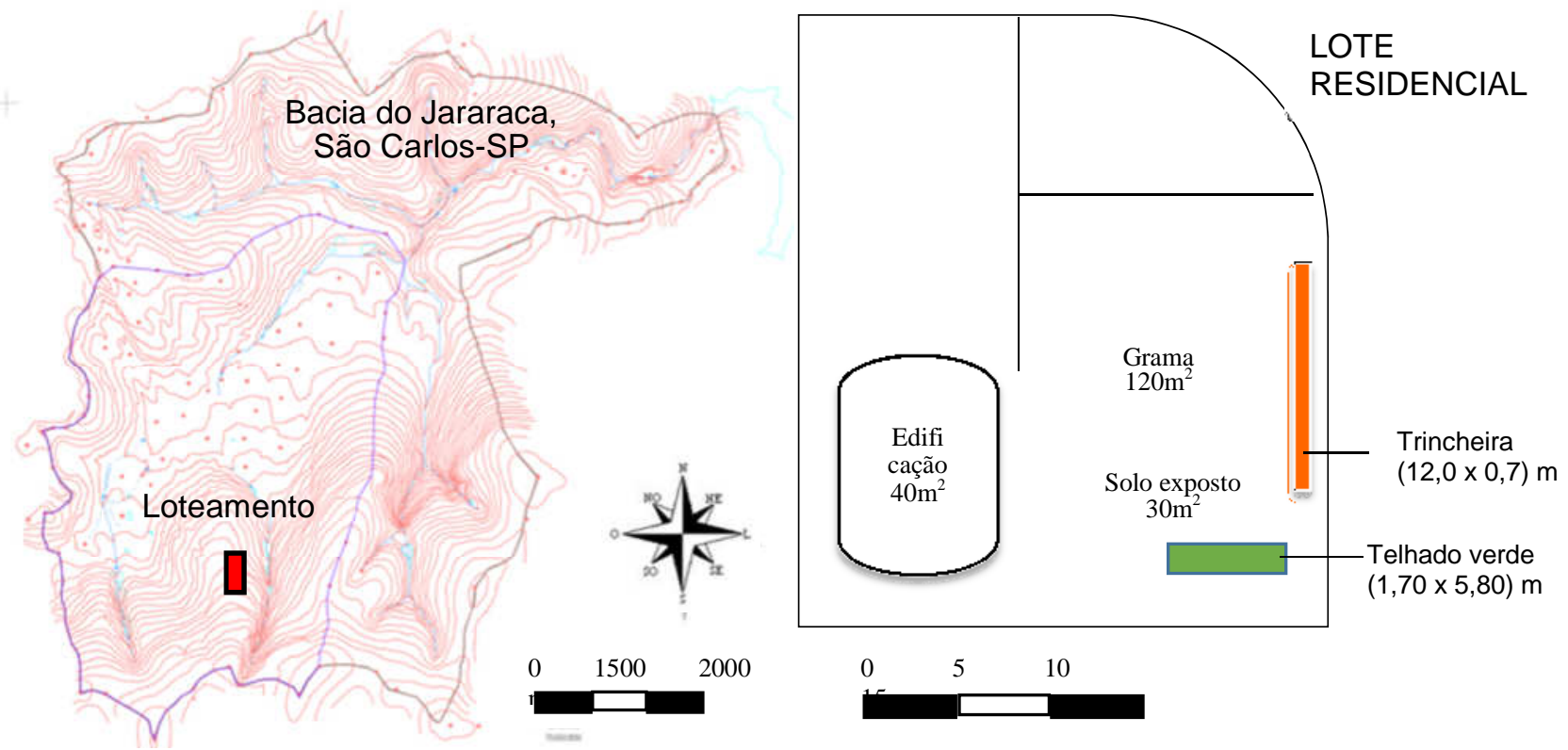

Figura 1. Localização do loteamento na bacia e cenário com dispositivos de retenção.

A Tabela 2 expressa às características físicas principais de cada dispositivo e volumes de armazenamento correspondentes. As medidas utilizadas são: largura $(B)$, comprimento $(L)$, altura $(H)$, área $(A)$, porosidade do solo ou brita (Ø) e volume (V).

Tabela 2. Características físicas das técnicas compensatórias instaladas no lote.

\begin{tabular}{lcrcccc}
\hline Dispositivo & $\mathbf{B}(\mathbf{m})$ & $\mathbf{L}(\mathbf{m})$ & $\mathbf{H}(\mathbf{m})$ & $\mathbf{A}\left(\mathbf{m}^{2}\right)$ & $\boldsymbol{\varnothing}(\%)$ & $\mathbf{V}\left(\mathbf{m}^{\mathbf{3}}\right)$ \\
\hline Telhado Verde & 1,70 & 5,80 & 0,20 & 10,00 & $53^{(\mathbf{a})}$ & 1,05 \\
Trincheira de Infiltração & 0,70 & 12,60 & 0,80 & 9,00 & $45^{(\mathbf{b})}$ & 7,00 \\
\hline
\end{tabular}

NOTA: B: largura; L: comprimento; H: altura; A: área; Ø: porosidade; V: capacidade volumétrica de armazenamento; ${ }^{(a)}$ porosidade do solo; ${ }^{(b)}$ porosidade da brita.

Os equipamentos utilizados para monitorar os volumes afluentes e efluentes consistem de linígrafos automáticos embutidos na saída de cada 
dispositivo e dados pluviométricos obtidos por estação meteorológica instalada no próprio lote de forma obter os volumes afluentes e efluentes.

Dadas às condições na escala do lote, o método racional foi considerado para se obter os volumes afluentes na trincheira de infiltração e no telhado verde a partir da equação (1).

$$
V_{a f}=\frac{c \times P \times A}{1000}
$$

Sendo, $V_{a f}$ : volume afluente $\left(\mathrm{m}^{3}\right) ; c$ : coeficiente de escoamento; $P$ : precipitação $(\mathrm{mm})$ e $A$ : área de contribuição $\left(\mathrm{m}^{2}\right)$.

$\mathrm{Na}$ trincheira de infiltração, parte do volume afluente torna-se efetivo devido às condições de saturação do solo, o que proporciona armazenamento temporário dentro da trincheira, calculado pela equação (2):

$V_{\text {armaz }}(t)=\left\{\frac{\left.\left[2 \cdot \frac{[(t)}{h_{0}} \cdot(B-b)+b\right]+b\right]}{2} \cdot h(t)\right\} \cdot \frac{h(t)}{h_{0}} \cdot \frac{L}{2} \cdot \emptyset_{b}$

Sendo, $V_{\text {armaz: }}$ volume de armazenamento $\left(\mathrm{m}^{3}\right) ; h(t)$ : nível medido dentro da trincheira $(\mathrm{m}) ; h_{0}$ : altura da trincheira $(\mathrm{m}) ; b$ : base menor da seção transversal da trincheira $(m)$; $B$ : base maior da seção transversal da trincheira (m); L: comprimento da trincheira $(\mathrm{m}) ; \varnothing_{b}$ : porosidade da brita.

A precipitação efetiva na trincheira de infiltração é definida como a lâmina de armazenamento temporária dentro do dispositivo, obtida pela relação entre o volume armazenado $V_{a r m a z}$ e o volume afluente $V_{a f}$. Ainda que não haja escoamento superficial sobre a trincheira, o valor da precipitação efetiva é calculada para se obter a eficiência na retenção do dispositivo. A precipitação efetiva, como sendo originalmente a parcela do escoamento superficial do lote, é obtida pelo monitoramento do escoamento superficial na saída do lote. $O$ coeficiente de escoamento é calculado pela relação entre a precipitação efetiva e a precipitação total.

No telhado verde a precipitação efetiva é a parcela da precipitação total que não fica retida nas camadas e no substrato do telhado verde, cujo volume é armazenado no reservatório de coleta do escoamento das águas pluviais do dreno de saída do telhado verde. O volume armazenado nesse reservatório é calculado pela multiplicação do nível registrado no linígrafo pela área em planta do reservatório. A relação entre o volume escoado no dreno de saída do 
telhado verde e o volume total precipitado ou volume afluente resulta 0 coeficiente de escoamento do telhado verde, que também pode ser obtido pela relação entre a precipitação efetiva e a precipitação total.

Para o cálculo da eficiência da retenção de águas pluviais nos dispositivos instalados, utilizou-se a relação entre a precipitação total e a precipitação efetiva ou o coeficiente de escoamento do dispositivo. A equação (3) considera os ângulos correspondentes.

$E_{r} T R(\%)=100 \times\left(1-\frac{\alpha}{\beta}\right)$

Sendo,

ErTR = eficiência na retenção hídrica do dispositivo;

$\alpha=$ ângulo correspondente ao $\mathrm{C}_{\mathrm{e}}$ do dispositivo $\mathrm{e}$

$\beta$ = ângulo correspondente ao $\mathrm{C}_{\mathrm{e}}$ sem o dispositivo.

O ângulo $\beta$ é a representação da relação entre a parcela do escoamento superficial, correspondente à precipitação efetiva, e a precipitação total, cujo cenário sem o dispositivo é a ocupação tradicional. A precipitação efetiva gerada pela ocupação sem a trincheira tem como resultado o valor do escoamento gerado na saída do lote somado ao volume do armazenamento temporário. O cenário sem telhado verde ou sem controle é a substituição do telhado verde por telhado cerâmico. Nessas condições, o telhado cerâmico foi constituído para geração de escoamento de cerca de $90 \%$ do total precipitado.

\section{RESULTADOS E DISCUSSÕES}

Os totais precipitados durante o período de análise de dados observados pela estação meteorológica instalada no lote estão cerca de $20 \%$ acima dos totais obtidos pelas estações vizinhas, baseado na média de precipitação mensal correspondente ao período de até 4 décadas retrospectivas e condições de dados históricos disponíveis. $\mathrm{Na}$ análise de consistência pelo Método de Curva Dupla Massa, os resultados revelam boa homogeneidade na relação de dados disponíveis pela estação instalada no lote com as estações pluviométricas vizinhas: CIIAGRO (Figura 2), DAEE (Figura 3) e INMET. 
Figura 2. Curva Dupla Massa entre estação do lote e CIIAGRO.

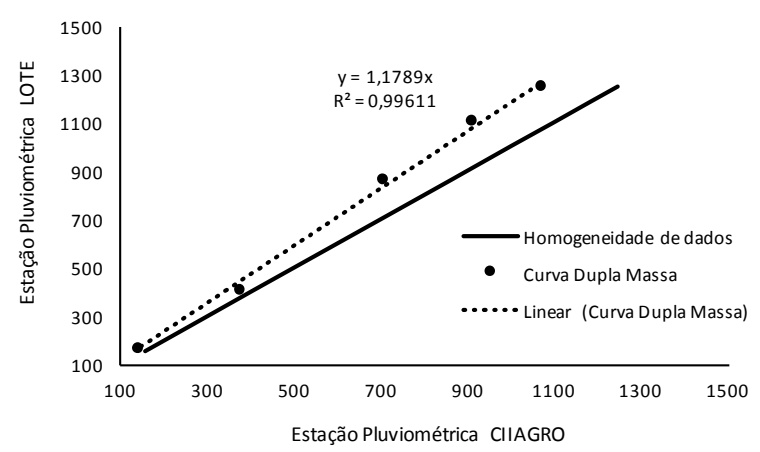

Figura 3. Curva Dupla Massa entre estação do lote e DAEE.

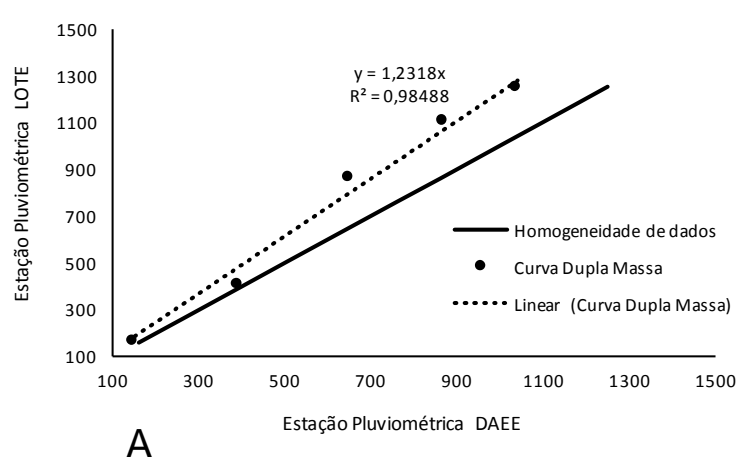

A

série histórica de dados de precipitação obtida das estações CIIAGRO (Figura 2), DAEE (Figura 3) e INMET, vizinhas à estação no lote experimental, apresentou respectivamente $99.6 \%, 98.5 \%$ e $98.2 \%$ de grau de homogeneidade. A declividade de cada reta pontilhada gerada pela Curva Dupla Massa indica o fator de proporcionalidade correspondente as séries dos postos vizinhos com o posto em análise do lote. As diferenças de declividade das retas ocorrem por erros sistemáticos do pluviômetro, alterações climáticas, e pequenas variações do regime pluviométrico dadas às distâncias entre os postos.

A partir dos dados consistidos de precipitação determinados pelo pluviômetro instalado no lote foram calculados os volumes de entrada e de saída nos dispositivos instalados no lote, como: os volumes afluentes ou precipitados, os volumes de armazenamento temporário ou de infiltração e os volumes efluentes do telhado verde e de saída no lote. Também foram determinadas as lâminas correspondentes à precipitação acumulada e a precipitação efetiva em cada dispositivo.

Baseado na equação (3) apresentada e ao calcular o ângulo $\beta$ de aproximadamente $5,5^{\circ}$ e $\alpha$ com ângulo de $30,2^{\circ}$, estimou-se uma eficiência na retenção do escoamento pela trincheira de até $82 \%$. Este valor indica a eficiência máxima da retenção hídrica pela trincheira quando comparado com o sistema sem controle de armazenamento das águas pluviais (Figura 4).

A eficiência de $36 \%$ na retenção hídrica de águas pluviais pelo telhado verde em comparação com telhado cerâmico foi obtida ao monitorar o volume escoado correspondente a precipitação efetiva do telhado verde $\left(\mathrm{P}_{\mathrm{e}} T \mathrm{~V}\right)$. Como 
referência, o telhado cerâmico constitui $90 \%$ de escoamento do total precipitado $\mathrm{P}_{\mathrm{e}} \mathrm{SC}$ (Figura 5).

Figura 4. Eficiência na retenção pela trincheira de infiltração.
Figura 5. Eficiência na retenção pelo telhado verde.
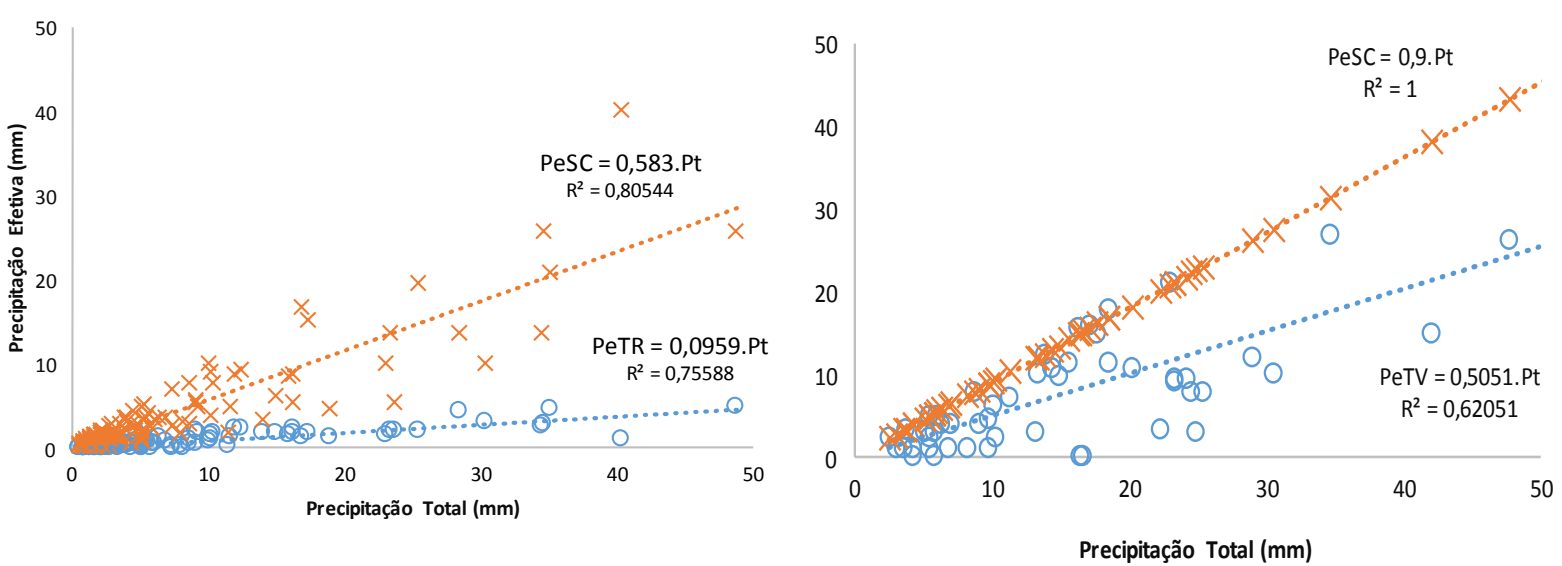

Ambos dispositivos favorecem a redução do coeficiente de escoamento de forma armazenarem parte do volume precipitado. Com a trincheira de infiltração, a retenção é maior ao amortecer grandes volumes precipitados $\left(\mathrm{P}_{\mathrm{e}} \mathrm{TR}\right)$. Sem a trincheira de infiltração instalada no lote, em determinados eventos podem ocorrer volumes de escoamento superficial $\left(\mathrm{P}_{\mathrm{e}} \mathrm{SC}\right)$ iguais aos totais precipitados, sobretudo nas condições de umidade máxima ou de saturação do solo.

No cálculo da eficiência são considerados dados observados no monitoramento, como: precipitação total e precipitação efetiva ou volume de escoamento superficial (Tabela 3).

Tabela 3. Balanço hídrico das técnicas compensatórias.

\begin{tabular}{lccc}
\hline Cenário & $\begin{array}{c}\text { Precipitação Total } \\
(\mathbf{m m})\end{array}$ & $\begin{array}{c}\text { Escoamento } \\
(\mathbf{m m})\end{array}$ & $\begin{array}{c}\text { Retenção } \\
(\mathbf{m m})\end{array}$ \\
\hline Lote com trincheira & 882 & 88 & 794 \\
Lote sem trincheira & 882 & 511 & 371 \\
\hline Telhado Verde & 810 & 405 & 405 \\
Telhado Cerâmico & 810 & 729 & 81 \\
\hline
\end{tabular}

A metodologia de cálculo da eficiência na retenção das águas pluviais considera tanto a capacidade de retenção baseado na parcela do volume de escoamento gerado pelo dispositivo como na ocupação sem o dispositivo. Nas análises de eventos sub-diários de precipitação foram desconsideradas perdas por evapotranspiração. 
Ao analisar resultados estatísticos dos eventos sub-diários a partir da variação do comportamento da relação entre a precipitação efetiva e a precipitação total observada no lote com a trincheira de infiltração, o coeficiente de escoamento máximo obtido foi de 0,37 , enquanto $25 \%$ do total dos eventos sub-diários obtiveram valor acima de 0,14 e mediana de 0,09. Sem a trincheira de infiltração instalada no lote, $25 \%$ dos eventos de precipitação resultaram coeficiente de escoamento acima de 0,83 e mediana de 0,60 (Figura 6). Os dados estatísticos que relacionam o comportamento da retenção das águas pluviais no telhado verde resultaram máxima de 0,95 do total dos eventos observados, sendo que $25 \%$ apresentaram resultados de coeficiente de escoamento com valor acima de 0,74 e mediana de 0,49 (Figura 7).

Figura 6. Box-pot de variação do coeficiente de escoamento para lote com e sem a trincheira.

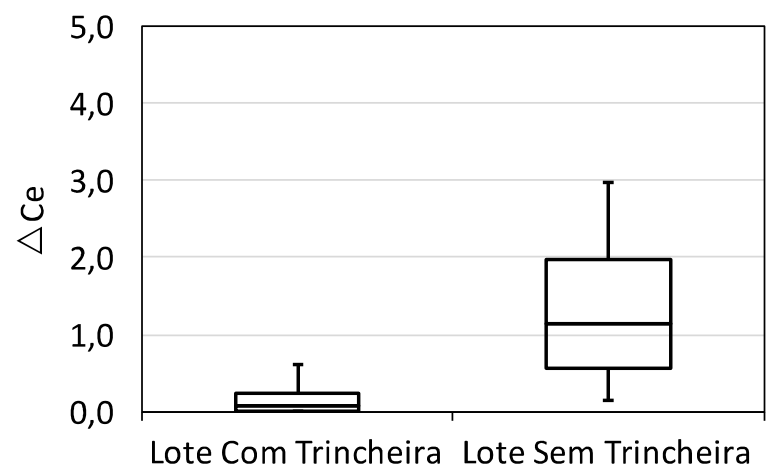

Figura 7. Box-pot de variação do coeficiente de escoamento do telhado verde e telhado cerâmico.

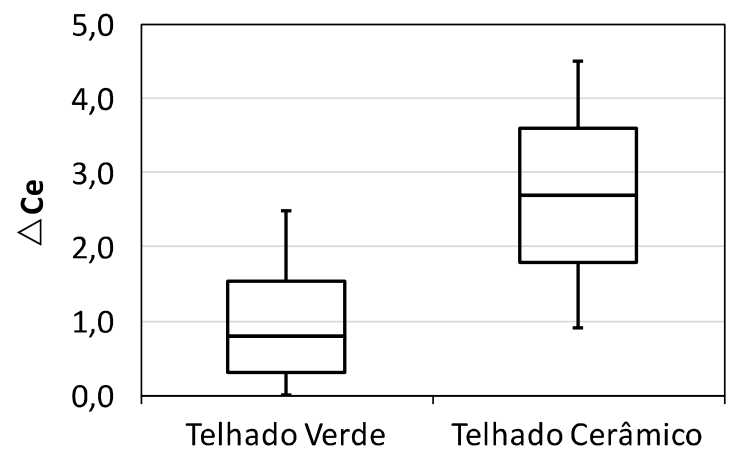

Ambos dispositivos - trincheira de infiltração e telhado verde revelaram, portanto níveis de eficiência que podem ser avaliados de acordo com a capacidade de armazenamento de águas pluviais em relação à um cenário sem controle - lote sem a trincheira e telhado cerâmico. A tendência de lotes ocupados de forma tradicional eleva os volumes escoados à medida que deixam de infiltrar às águas pluviais ou que ficam retidos ou armazenados no solo.

A análise da eficiência da retenção hídrica das águas pluviais é definida como sendo uma medida que objetiva proporcionar melhorias no manejo de técnicas compensatórias em lotes urbanos, com a redução do escoamento superficial na escala de microdrenagem. 


\section{CONCLUSÕES}

As análises de consistência dos dados pluviométricos obtidas na área de estudo a partir da estação pluviométrica do lote e os postos CIIAGRO, DAEE e INMET, apresentaram resultados de homogeneidade acima de $98 \%$ pela Curva de Dupla Massa, sendo considerados bastante adequados para estações distantes até $8,3 \mathrm{~km}$ da estação em análise.

Ao incorporar técnicas compensatórias de drenagem de águas pluviais em lote urbano, como trincheira de infiltração e telhado verde, ganha-se eficiência na retenção das águas pluviais de até $82 \%$ quando comparados com lotes ocupados tradicionalmente.

A utilização de dispositivos de retenção de águas pluviais em áreas particulares de pequena escala favorece a redução dos impactos locais e contribui para diminuir a manutenção no sistema de microdrenagem. Espera-se ampliar o estudo na integração das técnicas compensatórias na metodologia de cálculo de eficiência na retenção das águas pluviais.

\section{REFERÊNCIAS BIBLIOGRÁFICAS}

CEPAGRI. Centro de Pesquisas Meteorológicas e Climáticas Aplicadas a Agricultura. Universidade de Campinas, UNICAMP. Disponível em: <http://www.cepagri.unicamp.br/>. Acesso em 25 abril 2015.

CIIAGRO. CENTRO INTEGRADO DE INFORMAÇÕES AGROMETEOROLÓGICAS. CIIAGRO. Monitoramento Climatológico. Centro Integrado de Informações Agrometeorológicas. Dados pluviométricos da plataforma online. Disponível em: <http://www.ciiagro.sp.gov.br/> Acesso em 25 abril 2015.

DAEE-SP. Departamento de Águas e Energia Elétrica, São Paulo-SP. Dados pluviométricos online, DAEE-SP. Disponível em: <http://hidroweb.ana.gov.br/>. Acesso em 25 abril 2015.

GRIMMOND, C.S.B.; OKE, T.R. An evaporation-interception model for urban areas. Water Resources Research 27: 1739-1755, 1991.

LERNER, D. N. Too much or too little: recharge in urban areas. In Groundwater in the Urban Environment, Vol. 1, Processes and management, Chilton $\mathrm{J}$ et al. (eds). Balkema: Rotterdam; 41-47, 1997.

MCCUEN, R. H.; MOGLEN, G. E. Multicriterion Stormwater Management Methods. Journal of Water Resources Planning and Management. V. 114, n.4, p. 414-431. Jul, 1988.

OHNUMA JR, A.A. Medidas não convencionais de reservação d'água e controle da poluição hídrica em lotes domiciliares. Tese de doutorado. Escola de Engenharia de São Carlos, Universidade de São Paulo, EESC/USP, 306p, 2008.

OHNUMA JR, A.A.; ALMEIDA NETO, P; MENDIONDO, E.M. Análise da Retenção Hídrica em Telhados Verdes a Partir da Eficiência do Coeficiente de Escoamento, Revista Brasileira de Recursos Hídricos, Volume 19 n.2, 41-52, 2014. 
OWEN, C. R. Water budget and flow patterns in an urban wetland. Journal of Hydrology. 169, p. 171-187, 1995.

PINTO, L.L.C.; MARTINS, J.R.S. Variabilidade da taxa de impermeabilização do solo urbano. In Anais do XXIII Congresso Latinoamericano de Hidráulica, Cartagena de Indias, Sep. 2008.

RAGAB, R.; et al. Experimental study of water fluxes in a residential area: 1. Rainfall, roof runoff and evaporation: the effect of slope and aspect. In: Hydrological Process. 17, p. 2409-2422, 2003.

SCHILLING, W. Cisterns against storms. In: Featherstone, R. E., James, A. (ed.). Urban drainage systems. Southampton: Computational Mechanics Centre, ch. 4, p. 49-60, 1982.

STEPHENSON, D., 1994. Comparison of the water balance for an undeveloped and a suburban catchment. Hydrological Sciences. 39: 295-307.

TUCCI, C. E. M. Drenagem Urbana. Gestão das Águas. p.36-37, 2004.

VAN DEN VEM, F. H. M. Water balance of urban areas. In Hydrological Processes and Water Management in Urban Areas, Massing H, Packman J, Zuidema F (eds). Publication No. 198, International Association Hydrological Sciences: Wallingford; p. 21 - 32, 1990.

WEI, W; JIAA, F; YANGA, L; ZHANGA, H; YUA, Y. Effects of surficial condition and rainfall intensity on runoff in a loess hilly area, China. Journal of Hydrology. v 513, p. 115-126. 2014.

WHITLOW, T. H.; BASSUK, N. L.; REICHERT, D. L. A 3-year study of water relations of urban street trees. Journal of Applied Ecology n. 29: p.436 - 450, 1992.

YANG, L; CHEN, L; WEI, W; YU, Y; ZHANG, H. Comparison of deep soil moisture in two revegetation watersheds in semi-arid regions. Journal of Hydrology. v 513, p. 314-321. 2014.

Recebido: 25/05/2015

Aprovado: 28/06/2015 